\title{
Metabolomics approach based on NMR spectroscopy and multivariate data analysis to explore the interaction between the leafminer Tuta absoluta and tomato (Solanum lycopersicum)
}

Bruna de Falco

Daniele Manzo

Guido Incertil

Antonio Pietro Garonna

Maria Ercolano

Vitginia Lanzotti

This is the peer reviewed version of the following article:

De Falco, B. Et al (2019). Metabolomics approach based on NMR spectroscopy andmultivariate data analysis to explore the interaction between the leafminer Tuta absolutaand tomato (Solanum lycopersicum), which has been published in final form at https://doi.org/10.1002/pca.2850 This article may be used for non-commercial purposes in accordance with Wiley Terms and Conditions for Self-Archiving. 
1 Metabolomics approach based on NMR spectroscopy and multivariate data analysis to explore

2 interaction between the leafminer Tuta absoluta and tomato, Solanum lycopersicum

3

4 Bruna de Falco ${ }^{\mathrm{a}, \mathrm{b}, \dagger}$, Daniele Manzo $^{\mathrm{a}, \dagger}$, Guido Incerti ${ }^{\mathrm{c}}$, Antonio Pietro Garonna ${ }^{\mathrm{a}}$ Maria

5 Ercolano $^{\mathrm{a}^{*}}$ and Virginia Lanzotti $\mathrm{a}^{*}$

6

7 a Department of Agricultural Sciences, University of Naples Federico II, Via Università 100,

880055 Portici, Naples, Italy

$9{ }^{\mathrm{b}}$ School of Science, Engineering \& Technology, Division of Food \& Drink, University of 10 Abertay, Bell Street, DD1 1HG Dundee, Scotland, UK

$11{ }^{\mathrm{c}}$ Department of Agri-Food, Animal and Environmental Sciences, University of Udine, Via 12 delle Scienze 206, 33100 Udine, Italy

13

14 "To whom correspondence should be addressed.

15 Tel.: +39 0812539459. E-mail address: lanzotti@ unina.it (V. Lanzotti).

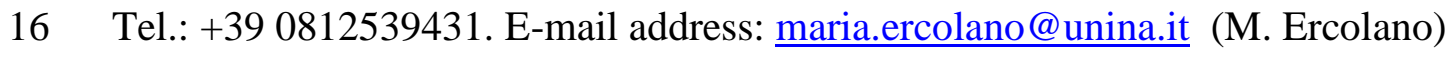

17

18

$19 \dagger$ These authors contributed equally to this work.

20

21

22 Running title: Metabolomics to explore interaction between Tuta absoluta and tomato 


\section{Abstract}

24 Introduction - Tuta absoluta (Meyrick) (Lepidoptera: Gelechiidae) is one of the most devastating and harmful pests of tomato (S. lycopersicum) crops causing up to 80-100\% yield losses. A large arsenal of plant metabolites is induced by the leafminer feeding including defense compounds that could differ among varieties.

Objective - To compare the metabolomic changes of different genotypes of tomato (tolerant “T”, susceptible "S" and F1 hybrid obtained between T and S) after exposition to T. absoluta. Methodology - Nuclear magnetic resonance spectroscopy followed by multivariate data analysis were performed to analyse the metabolic profiles of control and infested samples on three different tomato genotypes.

Results - Signals related to GABA ( $\gamma$-aminobutyric acid) were relatively much higher in all infested samples compared to the non-infested plants used as control. Infested $\mathrm{T}$ genotype samples were the most abundant in organic acids, including fatty acids (FA) and acyl sugars (AS), chlorogenic acid, neochlorogenic acid and feruloyl quinic acid, indicating a clear link between the exposure to leafminer. Results also showed an increase of trigonelline in all tomato varieties after exposition to T. absoluta.

Conclusion - Metabolomics approach based on NMR spectroscopy followed by multivariate data analysis allowed for a detailed metabolite profile of plant defences, providing fundamental information for breeding programmes in plant crops.

Keywords: NMR, Chemometrics, Tuta absoluta, Solanum lycopersicum, Plant-Pathogen Interaction. 


\section{Short Abstract}

47 Tuta absoluta (Lepidoptera: Gelechiidae) is one of the most devastating and harmful pests of 48 tomato crops. To promote the development of new tomato varieties resistant to this leafminer,

49 a metabolomics analysis followed by chemometrics on plant-pest interaction have been carried

50 out on three tomato genotypes. This study allowed to obtain a detailed metabolite profile of 51 plant defences providing fundamental information for improving plant crops. 


\section{Introduction}

53 Tomato crop (Solanum lycopersicum) is one of the most economically important vegetable worldwide with a very low-fat content and excellent source of antioxidants, dietary fibres, minerals and vitamins ${ }^{1}$. This crop is susceptible to a whole plethora of abiotic and biotic stress, translated in the most threatening and yield-loss damages ${ }^{2}$. Phytophagous insects represent a huge problem in global crop cultivation causing yield reductions and considerable costs in control measures. Among pathogens, Tuta absoluta (Meyrick) (Lepidoptera: Gelechiidae) is one of the most devastating and harmful pests of Solanaceous crops. If no control measures are taken, then the pest can cause up to $80-100 \%$ yield losses in tomato crops ${ }^{3}$. Larval feeding activity reduces the plants photosynthetically active surface and, consequently, growth and yields ${ }^{4}$. Control of T. absoluta is a worldwide necessity but the efficacy of foliar insecticides is inconsistent, as it may require many applications with undesirable effects (residues, damage to natural enemies, resistance to chemicals, etc). Chemical control to combat such threats is often too expensive for growers and, in some cases, ineffective ${ }^{5}$. Moreover, the use of pesticides has been reduced due to environmental and consumer constraints. Hence, the identification of resistant cultivars results to be one of the most important research goals for promoting a sustainable agriculture. In the last years, with the development of analytical instrumentations, data processing and chemometric tools, many studies have been performed to analyse plant-pathogen interactions ${ }^{1}$. Among the mechanisms by which plants can control the biotic or abiotic stress, the production of secondary metabolites as defensive response is the most common feature. In this framework a key role could be played by the development of new tomato varieties resistant to the leafminer. Resistance to T. absoluta has been found in several wild tomato accessions, such as Solanum pennellii (Lycopersicon pennellii) LA716 ${ }^{6}$ and S. peruvianum (L. peruvianum) NAV29 and NAV115 ${ }^{7}$. Several studies have enlightened 
confer resistance to T. absoluta. Metabolites production is the result of biochemical dynamics of living organisms starting with gene expression and affected by environmental conditions. Metabolomics can define the biochemical phenotype of the studied subject ${ }^{11}$. The aim of this research is to investigate the metabolic changes of different genotypes of tomato (tolerant " $\mathrm{T}$ ", susceptible "S" and F1 hybrid obtained between $\mathrm{T}$ and $\mathrm{S}$ ) after exposition to T. absoluta, in order to provide information about the chemical diversity of the signalling compounds involved in the defence response in plant-pest interaction.

\section{Experimental}

\section{Plant material}

Three tomato (Solanum lycopersicum) genotypes were provided by FARAO seed company (Sarno, Italy). A tolerant/partial resistant cherry type tomato BR221 (named as 'T') and a susceptible variety, PS650 (named as 'S') were used in the experiment. These two genotypes were furthermore used as parental lines (Tolerant x Susceptible) to obtain an F1 hybrid CS823 (named as 'F1'), also used in the experiment. ${ }^{12}$

Growth condition

3 A special tunnel $(500 \times 60 \times 90 \mathrm{~cm})$ protected by anti-insect net $(25 \mathrm{mesh}, 0.72 \times 0.97 \mathrm{~mm})$ was build up in a greenhouse to perform the infestation trials on $20 \mathrm{~cm}$ high tomato plants. A total of 120 plants were used for the experiment. The tunnel was divided by a septum in two adjacent cages. Each cage contained the three genotypes under study in a randomized complete block design consisting of 20 plants/replica for each genotype and for each condition. Half of the plants were exposed to infestation of 320 adults of $T$. absoluta and remained in the cage for at least 45 days, when an overall plant damage was visually assessed. Leaves with and without mines from each plant were collected and immediately frozen in liquid nitrogen. 
102 Chemicals First-grade dichloromethane and methanol were purchased from Delchimica

103 Scientific Laboratories Glassware (Naples, Italy). Deuterium oxide (99.8 atom \%D) and

104 dimethyl-4-silapentanesodium sulfonate (DSS) were obtained from ARMAR Chemicals

105 (Switzerland). Chloroform-d (99.8 atom \%D) containing 0.03\% (v/v) TMS, pure standard 106 amino acids, organic acids, sugars, chlorogenic acid and its derivatives were purchased 107 bySigma-Aldrich, Italy.

108 Extraction procedure

109 Leaves were collected in triplicates from each tomato variety, dried with liquid nitrogen and 110 powdered finely with a pestle and mortar. Three hundred milligrams of each sample were 111 dissolved in $5 \mathrm{~mL}$ of $\mathrm{CH}_{2} \mathrm{Cl}_{2} / \mathrm{MeOH} / \mathrm{H}_{2} \mathrm{O}$ in ratio of $2: 1: 1$, mixed by vortex and incubated 15

112 min at room temperature. To ensure efficient lysis of cell membranes and to promote the escape 113 of all metabolites, solution was sonicated for 1 min at $25^{\circ} \mathrm{C}$ with a Bandelin Sonoplus HD 2070.

114 Each mixture was centrifuged at $3000 \mathrm{rpm}$ for 30 minutes at room temperature and then the 115 aqueous and the organic fractions were accurately separated. The extraction was repeated 116 twice. The solvent of each extract was evaporated to dryness under vacuum at $30^{\circ} \mathrm{C}$ (Rotavapor

117 R-114, Büchi, Switzerland and Edwards Rotary Vane Pump) and the dry residues were kept at $118 \quad 4^{\circ} \mathrm{C}$ until NMR analysis.

119 NMR experiments

120 Dried aqueous fractions were diluted in $600 \mu \mathrm{l}$ of deuterium oxide $\left(99.8 \% \mathrm{D}_{2} \mathrm{O}\right)$ while dried 121 organic fractions were dissolved in $600 \mu \mathrm{l}$ of chloroform-d $\left(99.8 \% \mathrm{CDCl}_{3}\right)$ and transferred into 122 a $5 \mathrm{~mm}$ NMR tubes. DSS and TMS, both $0.03 \%(\mathrm{v} / \mathrm{v})$ in $\mathrm{D}_{2} \mathrm{O}$ and $\mathrm{CDCl}_{3}$, respectively, were 123 used as an internal standard for aqueous and organic fractions, respectively. The $\mathrm{pH}$ of aqueous 124 fractions was adjusted to 6.0 by using $\mathrm{KH}_{2} \mathrm{PO}_{4}$ as a buffering agent and $1 \mathrm{~N} \mathrm{NaOD}{ }^{13,14}$. The 125 NMR spectra were recorded at $298 \mathrm{~K}$ with Varian Unity Inova spectrometer operating at 
400.422 MHz. For each sample 200 transients were recorded using a spectral width of $12 \mathrm{ppm}$ on $32 \mathrm{~K}$ data points and relaxation delay $=0.04 \mathrm{sec}$. Chemical shifts were referred to DSS and TMS signals (both $0.00 \mathrm{ppm}$ ). All spectra were processed using iNMR program (www.inmr.net), phased and baseline corrected manually. Quantification was performed by

130 signal integration relative to the internal standard, DSS and TMS. The region of the solvent 131 peaks was excluded from the analysis. Spectral peak assignments of organic acids, amino acids, carbohydrates, chlorogenic acid and its derivatives were obtained on the basis of pure standards purchased by Sigma-Aldrich. Spectral peak assignments of these and the other detected metabolites were obtained by two-dimensional (2D) NMR experiments, including ${ }^{1} \mathrm{H}-{ }^{1} \mathrm{H}$ correlation spectroscopy (COSY) and ${ }^{1} \mathrm{H}^{-13} \mathrm{C}$ heteronuclear single-quantum correlation (HSQC) and comparison with data reported in the literature ${ }^{15-18}$. The COSY spectra were acquired with a spectral width of $6130 \mathrm{~Hz}$ in both dimensions, $8 \mathrm{~K}$ data points, and 512 increments with 32 transients per increment. The HSQC spectra were acquired with spectral widths of $8000 \mathrm{~Hz}$ in the F2 dimension and $25000 \mathrm{~Hz}$ in the F1 dimension, a data matrix with a size of $1 \mathrm{~K} \times 256$ data points, and 64 transients per increment. The obtained values showed a very good repeatability, with coefficient of variation among replicates $<2.5 \%$ for all signals. Multivariate Data Analyses

143 Multivariate analyses were applied to ${ }^{1} \mathrm{H}$ NMR spectral data from both aqueous and organic

144 fractions of leaves extracts. ${ }^{1} \mathrm{H}$ NMR spectra were preliminarily normalized and reduced to 145 integrated regions of equal widths (bins $=0.01 \mathrm{ppm}$ ), corresponding to $0-10 \mathrm{ppm}$ and 146 subsequently reduced to ASCII files using iNMR. ${ }^{11,17-19}$, Matrices were submitted to Principal 147 Component Analysis (PCA) ordination using the STATISTICA 7 Software (StatSoft Inc., 148 Tulsa, Oklahoma, USA). In a more detailed analysis on spectral data from the polar fraction, a 149 submatrix limited to the spectral data was considered and submitted to PCA. 


\section{Results and discussion}

152 To investigate the metabolites involved in the tomato-pest interaction, three different genotypes of S. lycopersicum were infested with T. absoluta and their metabolomic profiles were analysed

154 by NMR spectroscopy followed by chemometrics. ${ }^{1} \mathrm{H}$ NMR analysis of the aqueous and 155 organic extracts showed detailed metabolite profiles of Tolerant (BR221), Susceptible (PS650)

156 and F1 hybrid (CS823) genotypes infested with T. absoluta (Figures 1, S1 and S2). Both 157 primary and secondary metabolites were identified through NMR spectroscopy. While the organic extracts contained mainly fatty acids (FA) as the major compounds (Figure S2), the aqueous extracts were shown to contain metabolites belonging to different classes of

160 compounds. A representative model of each ${ }^{1} \mathrm{H}$ NMR Spectrum of the infested tomato plant extracts (T, F1 and S) is showed in Figure 1 in comparison with the corresponding non-infested tomato used as control. Triplicates of ${ }^{1} \mathrm{H}$ NMR spectra of the aqueous fractions for T, S and F1 infested with T. absoluta and the corresponding controls and reported in Figure S1. In particular, Figure 1 reports the indication of peaks related to the major metabolites identified in the spectra while full ${ }^{1} \mathrm{H}$ NMR assignments (chemical shifts and coupling constants) of the identified compounds are reported in Table 1. In particular, the presence of sucrose (Sucr) was observed by the appearance in the spectra of the characteristic anomeric signals at $\delta 5.25-5.29$, whose assignment was confirmed by the correlation peaks in the 2D NMR COSY spectra. In Figure 2 the COSY spectrum of the infested T variety is reported. In addition, signals for $\alpha$ and $\beta$-glucose ( $\alpha$ Glc and $\beta$ Glc) and for the related glucuronic acids ( $\alpha \mathrm{GlcU}$ and $\beta \mathrm{GlcU})$ were also observed (Table 1 and Figure 1). Organic acids such as malic (MA), shikimic (SHA) acid and GABA ( $\gamma$-aminobutyric acid) have been identified in the spectra with their related chemical shifts reported in Table 1. Further signals in the spectra were those related to complex fatty

174 acids (cFA) attached to sugar residues in the acyl sugars (AS). In the low-field region of ${ }^{1} \mathrm{H}$

175 NMR spectra most of the signals belong to secondary metabolites, such as the aromatics 
176 chlorogenic acid (cGA) and its derivatives, neo-chlorogenic acid (ncGA) and 5-O-feruloyl 177 quinic acid (FQA). Diagnostic peaks of the aromatic amino acids phenylalanine (Phe) and 178 tyrosine (Tyr) were also observed in this region of the spectra. All ${ }^{1} \mathrm{H}$ NMR data were then 179 integrated using iNMR programme and subjected to a detailed Principal Component Analysis 180 (PCA), in order to assess metabolomic differences among samples related to plant genotype and/or exposure to T. absoluta. Concerning the non-polar fraction, PCA of all spectral signals from $\mathrm{CDCl}_{3}$ extracts of tomato genotypes is shown in the right part of Figure 3. In particular, the samples from unexposed leaf (indicated in the figure with $\mathrm{Ctrl}$ ), irrespective of the plant variety, were consistently grouped together, at a short distance, in the topmost quadrant of the bi-dimensional space defined by the first two principal components, associated to signals resonating at 0.9-1.4 ppm. Moreover, samples exposed to T. absoluta (indicated in the figure with R) were arranged along a spatially ordered curve trajectory, but with no recognizable pattern related to plant variety. Interestingly, the sequence of exposed samples along the trajectory in the PC space corresponded to a progressively higher intensity of spectral signals resonating at 2.8-2.9, 5.4, and $2.1 \mathrm{ppm}$. These signals that are typical of unsaturated functionality on alkyl chain signals should be related with the plant exposure to the micromoth. Further analyses could help to clarify if such compounds are involved as by-products of the pest attack, or as active molecules playing a role in the defence mechanisms of tomato against T. absoluta. On the contrary, the bi-dimensional PCA plot of the ${ }^{1} \mathrm{H}$ NMR spectral data

195 from the aqueous fraction (Figure 3, left) clearly separated the samples based on plant 196 genotypes, with leaf materials from T, F1 hybrid and S lines being selectively distributed in 197 the bottom-left, top, and bottom-right quadrants, respectively. However, a higher dispersion was observed for F1 samples, indicating a higher heterogeneity of their spectra compared to Tolerant and especially Susceptible samples. In addition, replicates exposed to the leaf herbivore T. absoluta were not well separated from the unexposed controls, with the latter 
201 closely grouped around the PC space centre. This means that, in general, the spectral 202 contributions from the different reference compounds, corresponding to the selected spectral 203 signals [i.e. $\left.\delta_{\mathrm{H}} 0.4-0.6,2.3-2.4,2.7-2.8,4.3-4.5,5.0-9.0\right]$, were differently distributed among 204 and within genotypes and, moreover, consistent differences can be observed between exposed 205 samples and controls. In other words, existing metabolic differences among non-infested genotypes (i.e. control samples) were amplified after the exposure to the leaf herbivore. The corresponding bi-dimensional plot of signal loadings (Figure 4) has allowed to discuss more in detail the general trend of the association between the analyzed samples and the axis of the PC space. In particular, the first PC axis was positively associated to the signals resonating at $\delta_{\mathrm{H}}$ 2.7-2.8 and $\delta_{\mathrm{H}}$ 7.3-7.4, diagnostic of malic acid and phenylalanine, respectively, and negatively

211 to a rather wide spectral region including signals resonating at $\delta_{\mathrm{H}} 0.4-0.6,6.2-6.4,6.7-7.1,7.5$ 7.6, 8.6-8.7, and 8.9-9.0. Such signals are diagnostic of fatty acids $\left(\delta_{\mathrm{H}} 0.39-0.65\right)$, chlorogenic and neochlorogenic acids $\left(\delta_{\mathrm{H}} 6.19-6.27,7.00-7.10,7.42-7.67\right), 5-\mathrm{O}-\mathrm{feruloyl}$ quinic acid $\left(\delta_{\mathrm{H}}\right.$ 6.27-6.36, 7.00-7.10, 7.55-7.62) and trigonelline $\left(\delta_{\mathrm{H}} 8.96-9.03,8.62-8.75\right)$. The second PC axis was related to carbohydrate content, being positively associated with the signals resonating at $216 \delta_{\mathrm{H}} 5.0-5.6$, characteristic of sugars such as $\alpha-$ glucose $\left(\delta_{\mathrm{H}} 5.07-5.09\right)$ and sucrose $\left(\delta_{\mathrm{H}} 5.25-5.29\right)$, and negatively with the signals resonating at $\delta_{\mathrm{H}} 4.3-4.5$, characteristic of $\beta$-glucose $\left(\delta_{\mathrm{H}} 4.48\right.$ 4.51), and $\alpha$ - and $\beta$-glucuronic acid ( $\left.\delta_{\mathrm{H}} 4.37-4.44\right)$. A more detailed characterization of metabolites elucidated with the ${ }^{1} \mathrm{H}$ NMR analysis has been carried out, by comparing the association between the PC axis and the spectral signal loadings (i.e. coloured arrows in the graph) with the samples scores in the PC space (i.e. sample locations in the graph) (Figure 4). In this way, both metabolomics of the three genotypes and the chemical changes (Figure 5) produced after the T. absoluta exposure, have been evaluated. First, S samples showed a higher content of malic acid (MA) and phenylalanine (Phe), which also increased after the exposure to the herbivore. Also, the $\mathrm{T}$ genotype showed MA production, but in smaller amounts 
compared to $\mathrm{S}$. On the contrary, the T genotype samples were the most abundant in organic acids, including Fatty Acids (FA), both free and as Acylsugars (AS), Chlorogenic acid (cGA), neochlorogenic acid (ncGA) and feruloyl quinic acid (FQA), detected in very small amounts in the Susceptible genotype. The content of these organic compounds was very low in control samples, indicating a clear link between the exposure and the metabolic pathways related to such specific organic molecules. Previously, it has been demonstrated that these compounds have negative effect on caterpillars ${ }^{20,21}$ as well as for different leaf beetles ${ }^{22-24}$. Content of the pyridinic alkaloid Trigonelline (TG) was also detected in all the three genotypes, with the T line showing the highest change of abundance. Trigonelline is an alkaloid with multiple regulatory functions in plants, such as cell cycle, nodulation, oxidative, UV and salt stress response, and DNA methylation ${ }^{25}$. Mirnezhad and colleagues $(2010)^{16}$ also identified very low amounts of trigonelline in some tomato varieties resistant to Frankliniella occidentalis, hypothesizing that this observation may be the result of a metabolic trade-off favouring the production of acylsugars. Results also showed an increase of TG after exposition of tomato to T. absoluta (Figure 5, bottom). The role of this alkaloid could be considered for further investigation in plant-herbivores interactions. The F1 genotype was distinctively different from the other two genotypes since it showed higher amounts of $\alpha$-glucose and sucrose and lower content in $\beta$-glucose and $\alpha$ - and $\beta$-glucuronic acids, whereas both $\mathrm{T}$ and $\mathrm{S}$ genotypes showed similar amounts of these carbohydrates. Furthermore, carbohydrates contents were always higher in infested samples than the non-infested, for all the three genotypes, indicating some connections between this aspect and the response to $T$. absoluta. Interestingly, signals related to GABA ( $\gamma$-aminobutyric acid) $\left(\delta_{\mathrm{H}} 2.3-2.4\right)$ were relatively much higher in infested samples of all genotypes compared to the corresponding non-infested controls. Consistently with our results, a physiological role of stress mitigation for GABA has been suggested, consistent with a stress-specific pattern of accumulation in plants ${ }^{26}$. Also, transgenic tobacco plants containing 
elevated GABA levels were resistant to root-knot nematodes ${ }^{27}$ and tobacco budworm larvae ${ }^{28}$.

252 Since GABA is a neurotransmitter in vertebrates and invertebrates, it could be produced by

253 plants to deter insect feeding, hypothesizing that its ingestion interferes with the normal

254 development of insects ${ }^{29}$. All these findings corroborate our assumption of a leading role of

255 GABA in the interaction between tomato and T. absoluta, even if no particular differences

256 could be detected between Tolerant and Susceptible genotypes. In this study, a direct defence

257 has been well elucidated by the metabolome analysis, revealing an involvement of compounds

258 such as chlorogenic and neo-chlorogenic acids, GABA and pyridinic alkaloid trigonelline.

259 NMR spectroscopy coupled with multivariate data analyses demonstrated to be a very

260 successful tool to investigate plant-pathogen interaction. The F1 derived from the cross

261 between the Tolerant and Susceptible lines, is a commercialized variety that showed good agronomic performance and tolerance to T. absoluta. These findings could be very useful for better direct future tomato breeding in agricultural and horticultural crops.

\section{Acknowledgements}

267 NMR spectra were recorded at the "Laboratorio di Analisi strumentale", Dipartimento di 268 Farmacia, University of Naples Federico II. The assistance of Paolo Luciano is gratefully acknowledged.

\section{CONFLICT OF INTEREST}

275 The authors declare no competing financial interest. 


\section{References}

1. Chaudhary P, Sharma A, Singh B, Nagpal AK. Bioactivities of phytochemicals present in 296 tomato. J Food Sci Tech 2018; 55:2833-2849.

297 2. Mazzei P, Vinale F, Woo SL, Pascale A, Lorito M, Piccolo A. Metabolomics by proton 298 high-resolution magic-angle-spinning nuclear magnetic resonance of tomato plants treated 299 with two secondary metabolites isolated from Trichoderma. J Agric Food Chem 2016; $300 \quad 64: 3538-3545$ 
3. Cocco A, Deliperi S, Delrio G. Control of Tuta absoluta (Meyrick)(Lepidoptera: Gelechiidae) in greenhouse tomato crops using the mating disruption technique. J Appl Entomol 2013; 137:16-28.

4. Maffei ME, Mithöfer A, Boland W. Before gene expression: early events in plant-insect interaction. Trends Plant Sci 2007;12: 310-316.

5. Siqueira HÁA, Guedes RNC, Picanço M C Insecticide resistance in populations of Tuta absoluta (Lepidoptera: Gelechiidae). Agric Forest Entomol 2000;2: 147-153.

6. Castelo-Branco M, França FH, Cordeiro CM, Maluf WR, Resende AM. Seleção em F2 (Lycopersicon esculentum $\times$ L. pennellii) visando resistência à traça do tomateiro. Hortic Bras 1987; 5:30-32.

7. Lourenção AL, Rossetto CJ, Miranda MD. Resistência de soja a insetos. IV. Comportamento de cultivares e linhagens em relação a Hedilepta indicata (Fabr.). Bragantia. 1985; 44:149-157.

8. de Azevedo SM, Faria MV, Maluf WR, De Oliveira AC, de Freitas JA. Zingiberenemediated resistance to the South American tomato pinworm derived from Lycopersicon hirsutum var. hirsutum. Euphytica 2003; 134:347-351.

9. Resende JTV, Maluf WR, Cardoso MDG, Nelson DL, Faria MV. Inheritance of acylsugar contents in tomatoes derived from an interspecific cross with the wild tomato Lycopersicon pennellii and their effect on spidermite repellence. Genet Molec Res 2002;1: 106-116.

10. Maluf WR, Barbosa LV, Santa-Cecília LC. 2-Tridecanone-mediated mechanisms of resistance to the South American tomato pinworm Scrobipalpuloides absoluta (Meyrick, 1917) (Lepidoptera-Gelechiidae) in Lycopersicon spp. Euphytica 1997; 93:189-194. analysis of Salvia. Phytochem Rev 2018; 17: 951-972. 
12. Manzo D. Integrated-omics approaches to explore tomato interaction with the leafminer Tuta absoluta. 2016. University of Naples Federico II, PhD thesis

13. Choi HK, Choi YH, Verberne M, Lefeber AW, Erkelens C, Verpoorte R. Metabolic fingerprinting of wild type and transgenic tobacco plants by ${ }^{1} \mathrm{H}$ NMR and multivariate analysis technique. Phytochemistry 2004; 65:857-864.

14. Choi YH, Sertic S, Kim HK, Wilson EG, Michopoulos F, Lefeber AW, Erkelens C, Prat Kricun SD, Verpoorte R. Classification of Ilex species based on metabolomic fingerprinting using nuclear magnetic resonance and multivariate data analysis. J Agric Food Chem 2005; 23; 53:1237-1245.

15. López-Gresa M P, Maltese F, Bellés J M, Conejero V, Kim H K, Choi Y H, Verpoorte R. Metabolic response of tomato leaves upon different plant-pathogen interactions. Phytochem Anal 2010; 21: 89-94.

16. Mirnezhad M, Romero-Gonzalez RR, Leiss KA, Choi YH, Verpoorte R, Klinkhamera PGL. Metabolomic analysis of host plant resistance to thrips in wild and cultivated tomatoes. Phytochem Anal 2010; 21: 110-117.

17. de Falco B, Incerti G, Pepe R, Amato M, Lanzotti V. Metabolomic fingerprinting of Romaneschi Globe Artichokes by NMR spectroscopy and multivariate data analysis. Phytochem Anal 2016; 27:304-314

18. de Falco B, Incerti G, Bochicchio R, Phillips TD, Amato M, Lanzotti V. Metabolomic analysis of Salvia hispanica seeds using NMR spectroscopy and multivariate data analysis. Ind Crops Prod 2017; 99:86-96.

19. Malmendal A, Amoresano C, Trotta R, Lauri I, De Tito S, Novellino E, Randazzo A. NMR spectrometers as "magnetic tongues": prediction of sensory descriptors in canned tomatoes. J Agric Food Chem 2011; 59: 10831-10838. 
20. Bernays EA, Oppenheim S, Chapman RF, Kwon H, Gould F. Taste sensitivity of insect herbivores to deterrents is greater in specialists than in generalists: a behavioral test of the hypothesis with two closely related caterpillars. J. Chem. Ecol 2000; 26: 547-563.

21. Beninger CW, Abou-Zaid MM, Kistner ALE, Hallett RH, Iqbal MJ, Grodzinski B, Hall JC. A flavanone and two phenolic acids from Crysanthemum morifolium with phytotoxic and insect growth regulating activity. J. Chem. Ecol 2004; 30: 589-606.

22. Fulcher AF, Ranney TG, Burton JD, Walgenbach JF, Danehower DA. Role of foliar

23. Ikonen A, Tahvanainen J, Roininen H. Chlorogenic acid as an anti herbivore defence of phenolics in host plant resistance of Malus taxa to adult Japanese beetles. Hort Sci 1998;

24. Jassbi AR. Secondary metabolites as stimulants and antifeedants of Salix integra for the leaf beetle Plagiodera versicolora. Z Naturforsch C 2003; 58:573-579.

25. Minorsky PV. The hot and the classic. Plant Physiol 2002; 130: 517.

26. Kinnersley AM, Turano FJ. Gamma aminobutyric acid (GABA) and plant responses to stress. Crit Rev Plant Sci 2000; 19:479-509.

27. McLean MD, Yevtushenko DP, Deschene A, Van Cauwenberghe OR, Makhmoudova A, Potter JW, Bown AW, Shelp BJ. Overexpression of glutamate decarboxylase in transgenic

28. MacGregor KB, Shelp BJ, Peiris S, Bown AW. Overexpression of glutamate decarboxylase tobacco plants confers resistance to the northern root-knot nematode. Molec Breed 2003;

29. Shelp BJ, Bown AW, McLean MD. Metabolism and functions of gamma-aminobutyric acid. Trends Plant Sci 1999; 4:446-452. 


\section{Tables}

376 Table 1. Full ${ }^{1} \mathrm{H}-\mathrm{NMR}$ assignment with chemical shifts and multiplicity in $400 \mathrm{MHz}$ spectrum

377 of tomato samples detected in $\mathrm{D}_{2} \mathrm{O}\left(\mathrm{KH}_{2} \mathrm{PO}_{4} \text { buffer } \mathrm{pH} 6.0\right)^{\text {a }}$

\begin{tabular}{|c|c|c|c|}
\hline Metabolites & Assignment & $\delta_{H}(p p m)$ & multiplicity $(\mathrm{J}$ in $\mathrm{Hz})$ \\
\hline $\begin{array}{l}\text { complex fatty acids } \\
\text { (cFA/AS) }\end{array}$ & $-\mathrm{CH}_{3}$ & $0.39-0.65$ & \\
\hline amino acids (AA) & & $0.94-2.10$ & \\
\hline glutamic acid (Glu) & $-\mathrm{COCH}_{3}$ & 2.10 & \\
\hline GABA & $-\mathrm{COCH}_{3}$ & $2.36-2.42$ & $\mathrm{t}(7.0)$ \\
\hline malic acid (MA) & $\mathrm{dd}(15.7,3.7)$ & $2-72-2.81$ & $\operatorname{dd}(15.7,3.7)$ \\
\hline & $\mathrm{dd}(8.9,3.7)$ & 4.40 & $\mathrm{dd}(8.9,3.7)$ \\
\hline aspartic acid (Asp) & & 2.81 & $\mathrm{dd}(17.4 ; 3.5)$ \\
\hline & & 2.65 & $\mathrm{dd},(17.4 ; 9.3)$ \\
\hline shikimic acid (SHA) & $\mathrm{CH}-4$ & $4.30-4.44$ & dd \\
\hline & $\mathrm{CH}-3$ & $6.71-6.82$ & $\mathrm{~s}$ \\
\hline$\alpha$-glucuronic acid ( $\alpha \mathrm{GlcU})$ & $\mathrm{CH}-5$ & $4.37-4.44$ & \\
\hline$\beta$-glucuronic acid ( $\beta \mathrm{GlcU})$ & $\mathrm{CH}-5$ & $4.37-4.44$ & \\
\hline$\beta$-glucose $(\beta \mathrm{Glc})$ & $\mathrm{CH}-1$ & $4.48-4.51$ & $\mathrm{~d}(7)$ \\
\hline$\alpha$-glucose $(\alpha \mathrm{Glc})$ & $\mathrm{CH}-1$ & $5.07-5.09$ & $d(3)$ \\
\hline sucrose (Sucr) & $\mathrm{CH}-1$ & $5.25-5.29$ & \\
\hline chlorogenic acid (cGA) & $\mathrm{CH}-8$ & $6.19-6.27$ & $\mathrm{~d}(16)$ \\
\hline (IUPAC: 5-O-caffeoyl & $\mathrm{CH}-6$ & $7.00-7.10$ & bd (9) \\
\hline quinic acid) & $\mathrm{CH}-7^{\prime}$ & $7.41-7.55$ & $\mathrm{~d}(16)$ \\
\hline neochlorogenic acid (ncGA) & CH-8, & $6.19-6.27$ & $\mathrm{~d}(16)$ \\
\hline
\end{tabular}




\begin{tabular}{llll}
\hline (IUPAC: 3-O-caffeoyl & CH-6' & $7.00-7.10$ & bd (9) \\
quinic acid) & $\mathrm{CH}-7$, & $7.42-7.67$ & $\mathrm{~d}(16)$ \\
tyrosine (Tyr) & 6.90 & $\mathrm{~d}(8)$ \\
5-O-feruloyl quinic acid & $\mathrm{CH}-8$, & $6.27-6.36$ & $\mathrm{~d}(16)$ \\
(FQA) & $\mathrm{CH}-6$, & $7.00-7.10$ & $\mathrm{bd}()$ \\
& $\mathrm{CH}-7$ ' & $7.55-7.62$ & $\mathrm{~d}(16)$ \\
phenylalanine (Phe) & $\mathrm{CH}-2-6$ & $7.34-7.41$ & \\
trigonelline (TG) & $\mathrm{CH}-1$ & $8.96-9.03$ & \\
& $\mathrm{CH}-3,5$ & $8.62-8.75$ & \\
\end{tabular}

${ }^{\mathrm{a} A s s i g n m e n t s ~ w e r e ~ p e r f o r m e d ~ b y ~ a n a l y s i s ~ o f ~ 1 D ~ a n d ~ 2 D ~ N M R ~ s p e c t r a ~ a n d ~ c o m p a r i s o n ~ w i t h ~ p u r e ~ s t a n d a r d s ~(s e e ~}$

379 Experimental) and reference data available in the literature. ${ }^{15-19}$

380

381 


\section{Figures}

383 Figure 1. ${ }^{1} \mathrm{H}$ NMR representative spectra in $\mathrm{D}_{2} \mathrm{O}$ at $400 \mathrm{MHz}$ of three tomato genotypes: $\mathrm{T}$, 384 tolerant (BR221); F1, hybrid (CS823); S, susceptible (PS650), infested with Tuta absoluta 385 (Tinf, F1inf, and Sinf) and non-infested control samples (Tctrl, F1crtl, and Sctrl) with 386 identification of the major compounds detected.

387 Figure 2. 2D COSY NMR spectrum $\left(\mathrm{D}_{2} \mathrm{O}, 400 \mathrm{MHz}\right)$ of infested tolerant tomato (Tinf).

388 Figure 3. PCA of ${ }^{1} \mathrm{H}$ NMR spectral data for polar (left) and non-polar (right) extracts of 389 tomatoes. Top: plot of sample scores. Symbol color and shape indicate plant variety (white, T; 390 grey: F1; black: S) and treatment (triangles: replicates exposed to infestant T. absoluta, squares: 391 unexposed controls), respectively. Bottom: plot of signal loadings. Labels in top and bottom 392 panels indicate sample ID and signal resonance ( $\mathrm{ppm})$, respectively.

393 Figure 4. PCA of selected reference ${ }^{1} \mathrm{H}$ NMR spectral signals for polar extract of tomatoes.

394 Left: plot of sample scores. Symbol color and shape indicate plant variety (white, T; grey: F1; 395 black: S) and treatment (triangles: replicates exposed to infestant $T$. absoluta, squares: 396 unexposed controls), respectively. Right: plot of signal loadings. Data labels indicate sample 397 ID and signal resonance (ppm), respectively.

398 Figure 5. Relative abundance (\%) of main metabolites detected by ${ }^{1} \mathrm{H}$ NMR analysis in $\mathrm{D}_{2} \mathrm{O}$ 399 extracts of tomato genotypes, except for fatty acids acquired in $\mathrm{CDCl}_{3}$ extract, as calculated 400 from spectral peak intensity. For each metabolite, peaks reported in Table 1 were considered. 401 Data refer to mean and standard deviation of 3 replicated spectra for each population. 


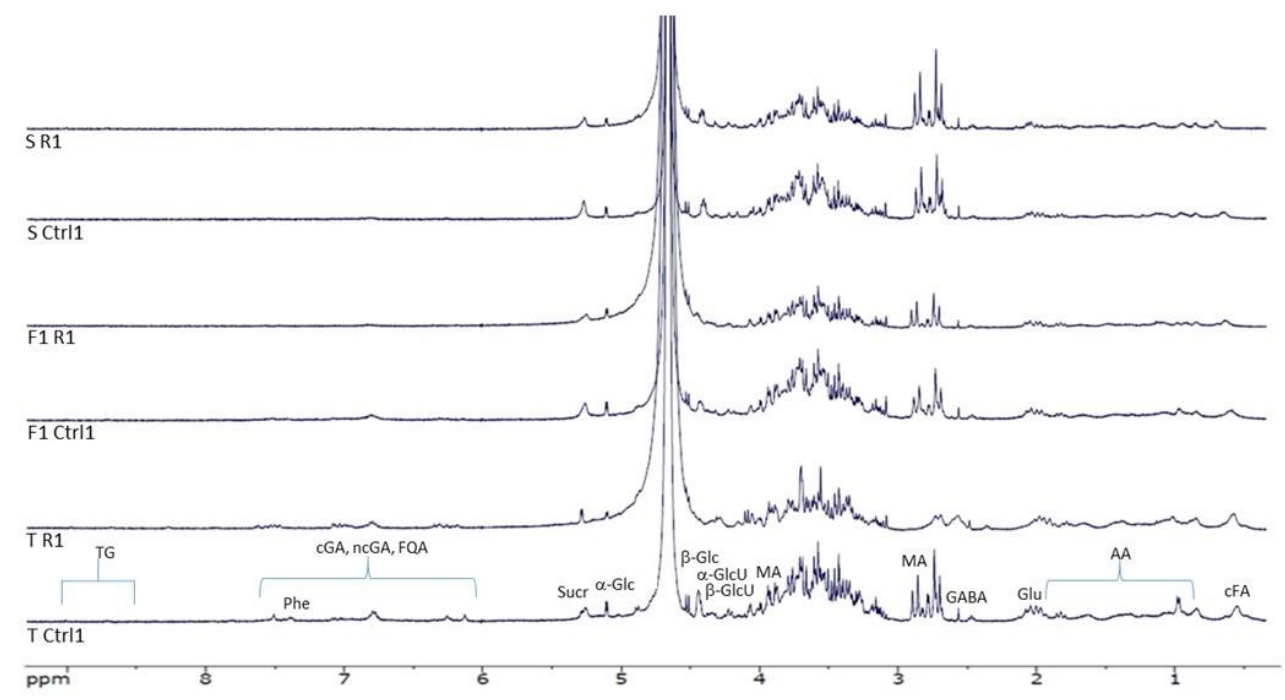

403

404 Figure 1. ${ }^{1} \mathrm{H}$ NMR representative spectra in $\mathrm{D}_{2} \mathrm{O}$ at $400 \mathrm{MHz}$ of three tomato genotypes: T, 405 tolerant (BR221); F1, hybrid (CS823); S, susceptible (PS650), infested with Tuta absoluta 406 (Tinf, F1inf, and Sinf) and non-infested control samples (Tctrl, F1crtl, and Sctrl) with 407 identification of the major compounds detected. 


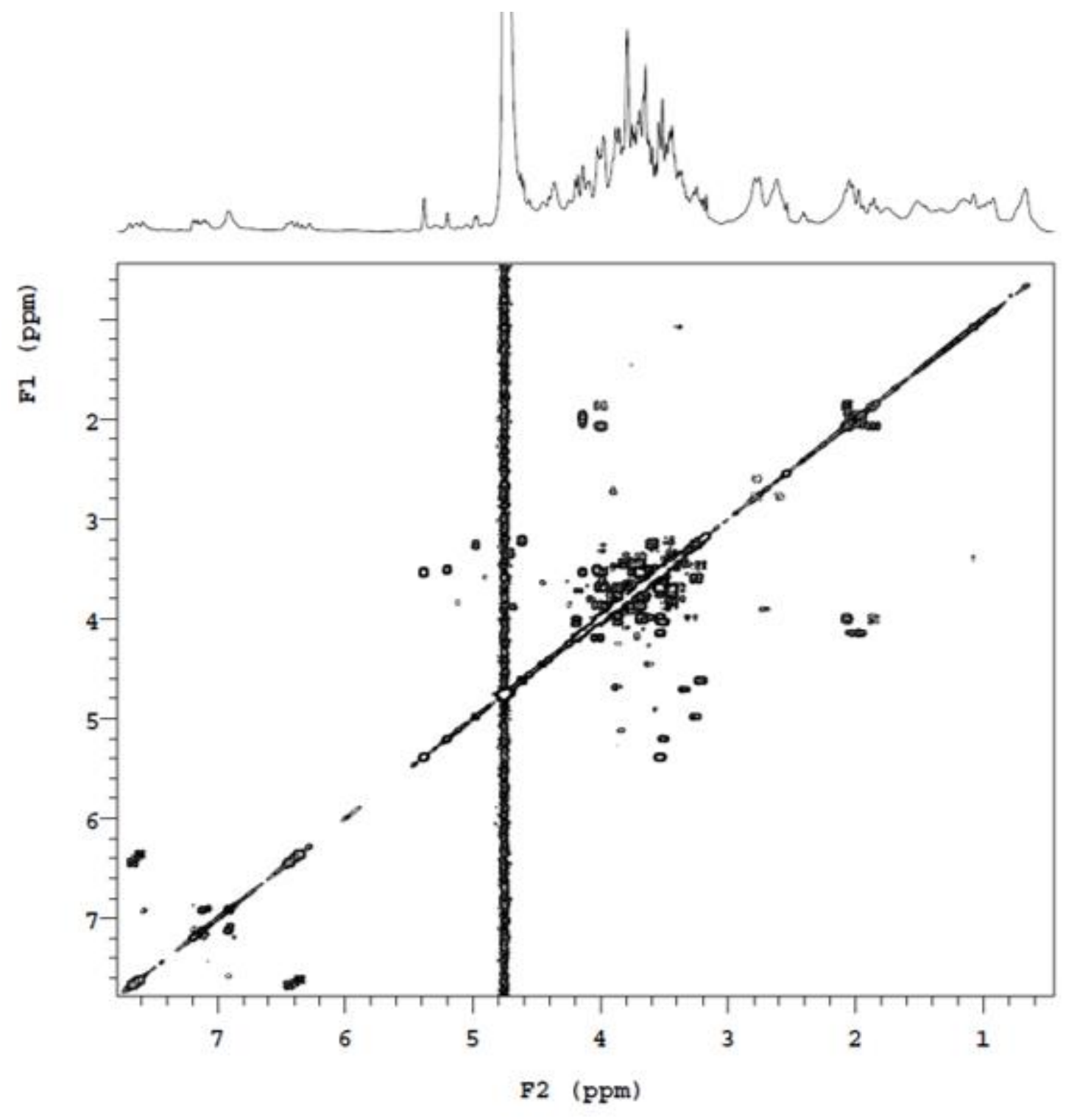

408

409 Figure 2. 2D COSY NMR spectrum $\left(\mathrm{D}_{2} \mathrm{O}, 400 \mathrm{MHz}\right)$ of infested tolerant tomato (Tinf).

410

411 
Polar fractions $\left(\mathrm{D}_{2} \mathrm{O}\right)$

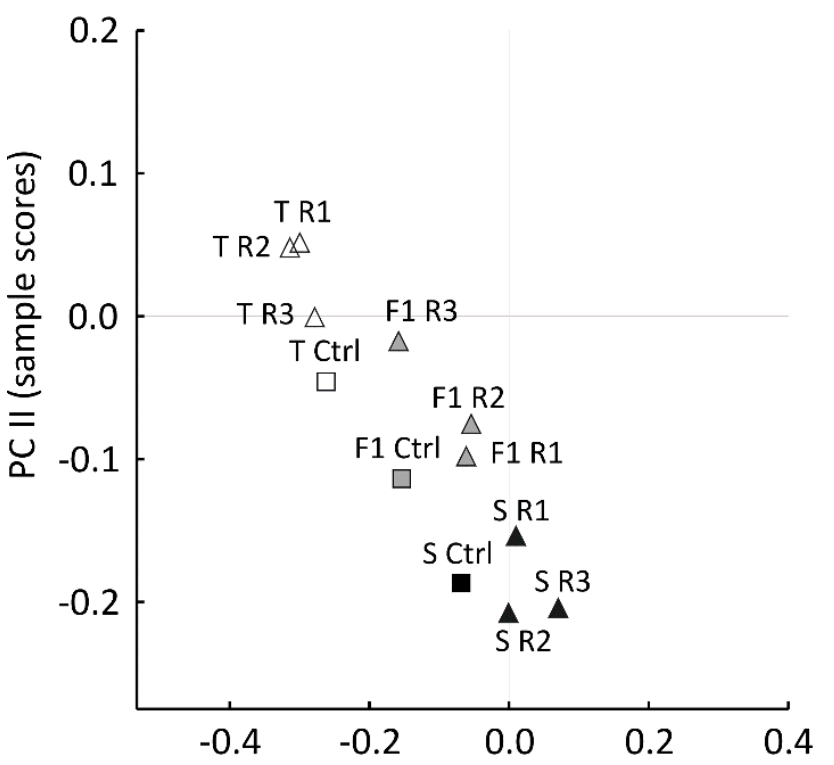

Apolar fractions $\left(\mathrm{CDCl}_{3}\right)$

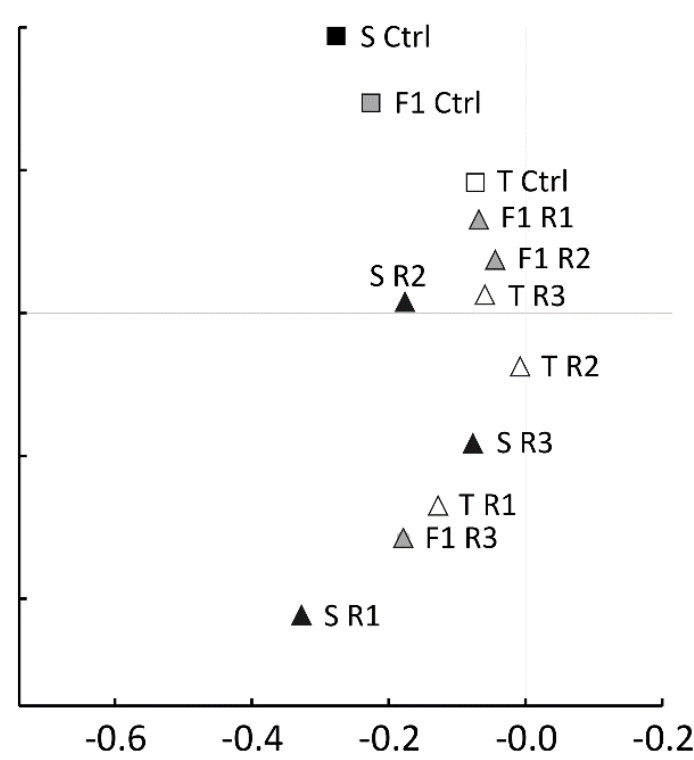

$\mathrm{PCI}$ (sample scores)
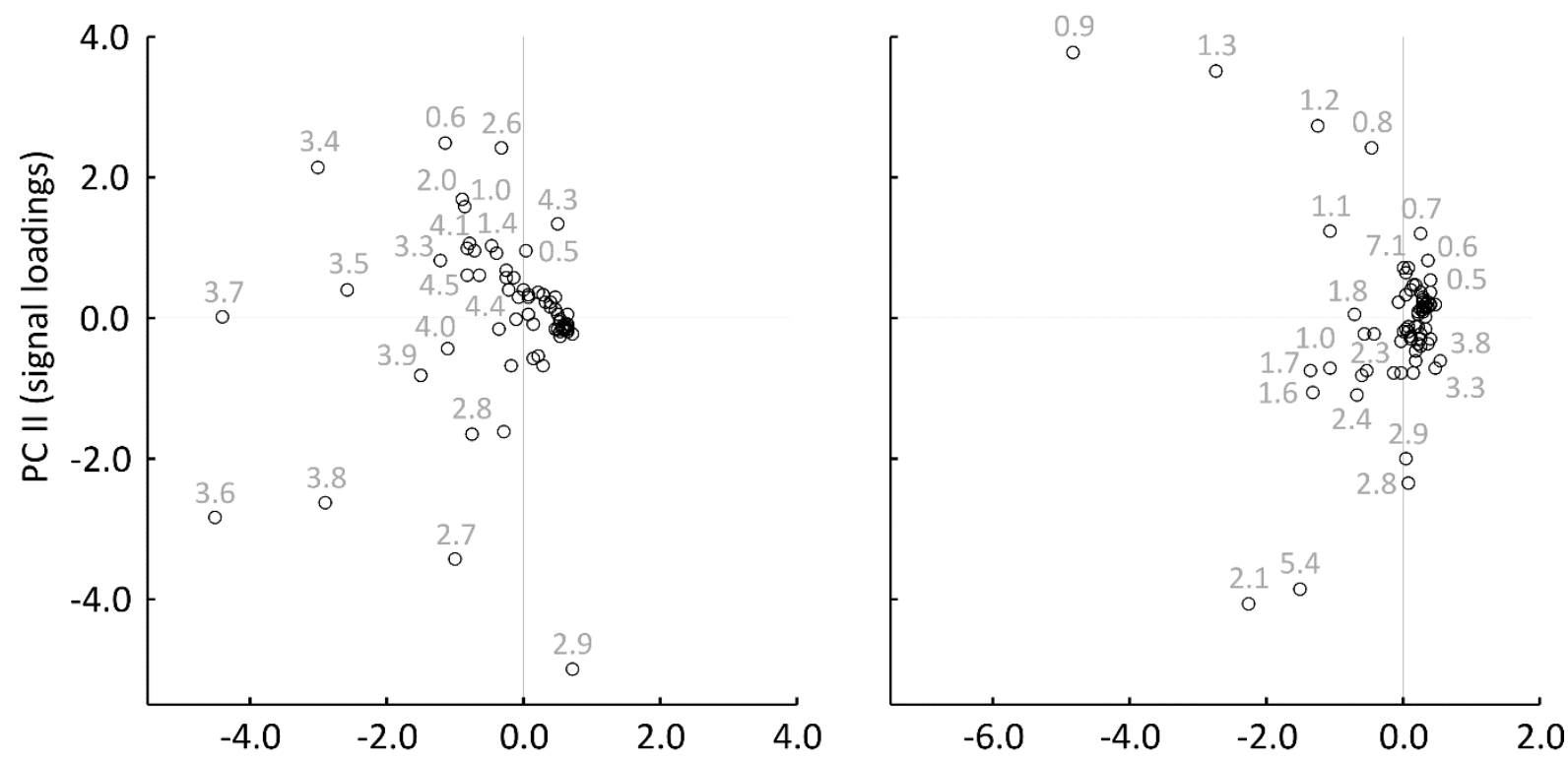

412

$\mathrm{PCI}$ (signal loadings)

413

414 Figure 3. PCA of ${ }^{1} \mathrm{H}$ NMR spectral data for polar (left) and non-polar (right) extracts of

415 tomatoes. Top: plot of sample scores. Symbol color and shape indicate plant variety (white, T;

416 grey: F1; black: S) and treatment (triangles: replicates exposed to infestant T. absoluta, squares:

417 unexposed controls), respectively. Bottom: plot of signal loadings. Labels in top and bottom

418 panels indicate sample ID and signal resonance (ppm), respectively. 

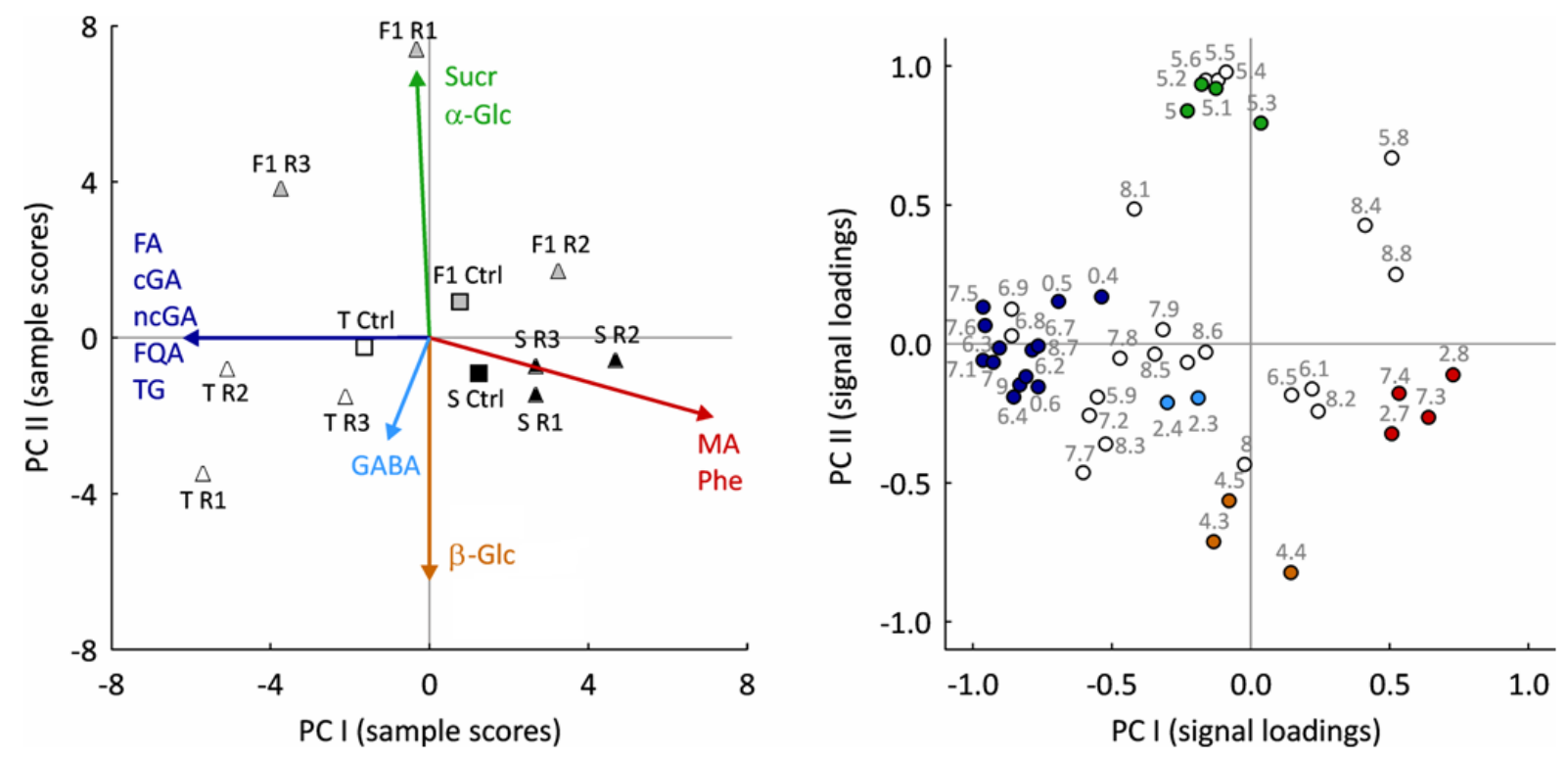

420 Figure 4 PCA of selected reference ${ }^{1} \mathrm{H}$ NMR spectral signals for polar extract of tomatoes.

421 Left: plot of sample scores. Symbol color and shape indicate plant variety (white, T; grey: F1;

422 black: S) and treatment (triangles: replicates exposed to infestant T. absoluta, squares:

423 unexposed controls), respectively. Right: plot of signal loadings. Data labels indicate sample

$424 \quad$ ID and signal resonance (ppm), respectively

425

426

427 

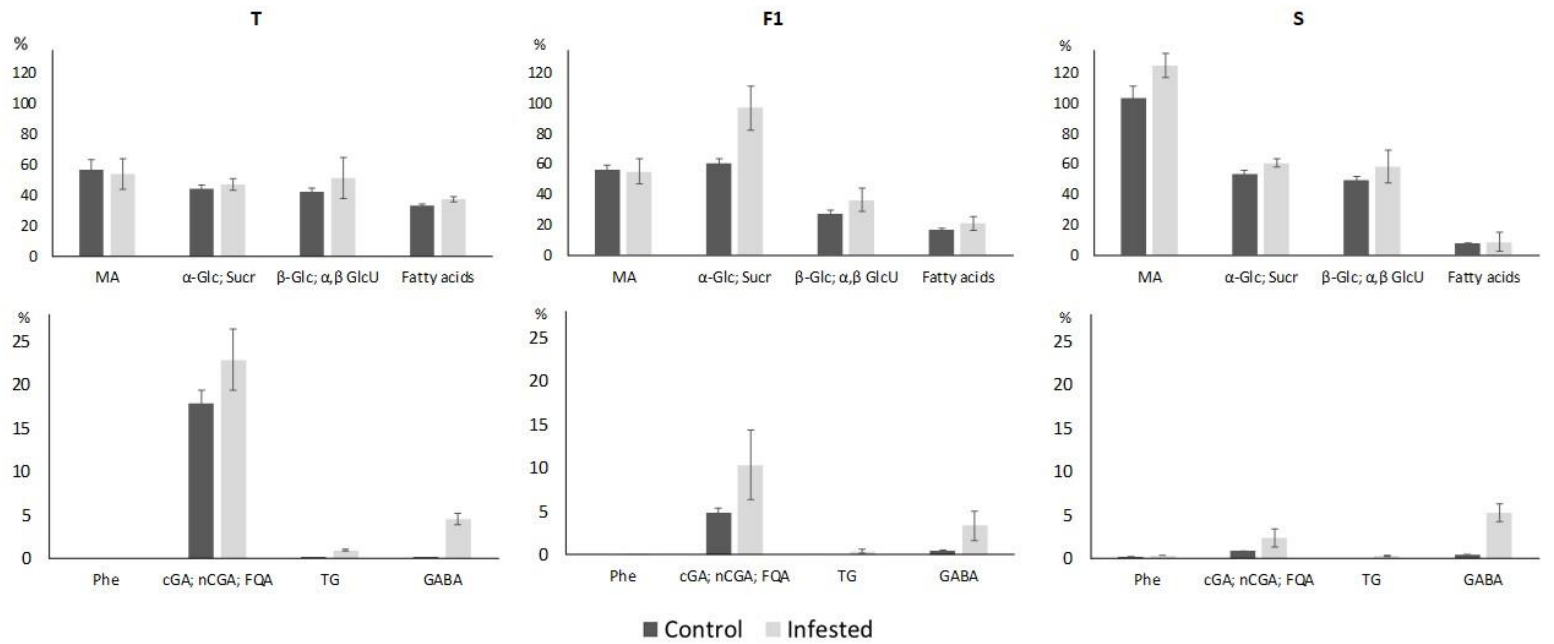

429 Figure 5. Relative abundance (\%) of main metabolites detected by ${ }^{1} \mathrm{H}$ NMR analysis in $\mathrm{D}_{2} \mathrm{O}$ 430 extracts of tomato genotypes, except for fatty acids acquired in $\mathrm{CDCl}_{3}$ extract, as calculated 431 from spectral peak intensity. For each metabolite, peaks reported in Table 1 were considered. 432 Data refer to mean and standard deviation of 3 replicated spectra for each population. 